\title{
BASE NACIONAL COMUM CURRICULAR E DIVERSIDADE SEXUAL E DE GÊNERO: (DES)CARACTERIZAÇÕES
}

\author{
BASE NACIONAL COMÚN CURRICULAR Y DIVERSIDAD SEXUAL Y DE GÉNERO: \\ DESCRIPCIONES
}

\author{
COMMON NATIONAL CURRICULAR BASE AND SEXUAL AND GENDER \\ DIVERSITY: DESCRIPTIONS
}

\author{
Caio Samuel Franciscati da SILVA ${ }^{1}$ \\ Ana Paula Leivar BRANCALEONI ${ }^{2}$
} Rosemary Rodrigues de OLIVEIRA ${ }^{3}$

RESUMO: Considerando a contemporaneidade da Base Nacional Comum Curricular, a presente investigação objetivou caracterizar possíveis concepções sobre diversidade sexual e de gênero mobilizados pelo referido documento oficial. Amparada por referenciais acerca da sexualidade no ambiente escolar e seguindo o paradigma qualitativo, esta pesquisa se configura como uma análise documental cujos dados foram coligidos segundo pressupostos da Análise Textual Discursiva. Os achados nos indicam que o documento oficial apresenta a sexualidade tão somente por meio de sua dimensão biológica em espaços restritos da área das Ciências da Natureza, figurando ao lado de conceitos vinculados às infecções sexualmente transmissíveis e à gravidez. A diversidade de gênero por sua vez, é silenciada ao longo do documento analisado, fato agravado pela superficialidade no tratamento dos direitos humanos.

PALAVRAS-CHAVE: Sexualidade. Gênero. Base Nacional Comum Curricular.

RESUMEN: Considerando la contemporaneidad de la Base Nacional Común Curricular, la presente investigación caracterizó posibles concepciones sobre diversidad sexual y de género presentes en el documento oficial. Con base en estudios sobre sexualidad en la escuela y de acuerdo con el paradigma cualitativo, realizamos un análisis documental en que los datos fueron examinados según el Análisis Textual Discursivo. Los resultados indican que el documento oficial presenta la sexualidad por medio de comprensiones biológicas en espacios restringidos a las Ciencias de la Naturaleza, junto con conceptos como infecciones sexualmente transmisibles y embarazo. La diversidad de género es silenciada por el documento analizado, hecho agravado por la superficialidad en el tratamiento de los derechos humanos.

\footnotetext{
1 Universidade Estadual Paulista (UNESP), Jaboticabal - SP - Brasil. Pós-doutorando. Departamento de Economia, Administração e Educação. ORCID: <https://orcid.org/0000-0002-4373-5002>. E-mail: caiofranciscati@gmail.com

2 Universidade Estadual Paulista (UNESP), Jaboticabal - SP - Brasil. Professora Assistente Doutora; Departamento de Economia, Administração e Educação. ORCID: <http://orcid.org/0000-0002-5927-4175>. Email: anapaulabrancaleoni@gmail.com

3 Universidade Estadual Paulista (UNESP), Jaboticabal - SP - Brasil. Professora Assistente Doutora; Departamento de Economia, Administração e Educação. ORCID: 〈http://orcid.org/0000-0002-1349-659X>. Email: oliveirose@fcav.unesp.br
}

RIAEE - Revista Ibero-Americana de Estudos em Educação, Araraquara, v. 14, n. esp. 2, p. 1538-1555, jul. 2019. E-ISSN: 1982-5587. 
PALABRAS CLAVE: Sexualidad. Género. Base Nacional Común Curricular.

ABSTRACT: Considering the contemporaneousness of the National Curricular Common Base, the present investigation characterized possible conceptions about sexual and gender diversity present in the official document. Based on studies on sexuality in school and according to the qualitative paradigm, we performed a documentary analysis in which data were examined according to the Discursive Textual Analysis. The results indicate that the official document presents sexuality through biological understandings in spaces restricted to the Natural Sciences, along with concepts such as sexually transmitted infections and pregnancy. Gender diversity is silenced by the analyzed document, a fact aggravated by superficiality in the treatment of human rights.

KEYWORDS: Sexuality. Gender. National Curricular Common Base.

\section{Introdução}

A sexualidade compreende o gênero, a identidade e a orientação afetivo-sexual, o erotismo, o prazer, a reprodução, etc., cuja expressão e experimentação pelos sujeitos ocorrem por meio de pensamentos, fantasias, desejos, valores, atitudes e relacionamentos, tanto no plano individual como no coletivo. Este entendimento amplo nos permite advogar que o ambiente escolar é permeado pela sexualidade e, assim sendo, deve favorecer a reflexão sobre suas várias dimensões, de modo a impedir quaisquer violências motivadas por discriminações e preconceitos contra a diversidade (CASTRO; ABRAMOVAY; SILVA, 2004; SEFFNER; PICCHETTI, 2014; LOURO, 2018). Todavia, a literatura pertinente aponta que as instituições escolares mantêm relações de negação da sexualidade, impedindo-a de adentrar em seus muros. Nesta perspectiva, a educação sexual ocorreu e ainda ocorre a partir de abordagens médicohigienistas que visam controlar a conduta sexual de seus atores (SILVA, 2004; ALTMANN, 2006; 2013; LOURO, 2018).

No que tange às políticas públicas voltadas à diversidade sexual e de gênero na escola, observamos avanços e retrocessos em diretrizes voltadas à educação. Destas diretrizes, cabe destacar os Parâmetros Curriculares Nacionais (PCN), especificamente o documento Tema Transversal Orientação Sexual, promulgados no ano de 1996. Apesar de problemáticas indicadas por diversos pesquisadores, como, por exemplo, o tratamento da sexualidade a partir de uma perspectiva biológica e a abordagem superficial das questões de gênero, o documento oficial corresponde à legitimação da abordagem da diversidade sexual e de gênero na escola 
(VIANNA; UNBEHAUM，2004; LEÃO; RIBEIRO，2012; VIANNA，2012; ABREU; SANTOS, 2015).

Recentemente, observamos em nosso país novas discussões sobre os enlaces e entraves entre diversidade sexual e de gênero e educação escolar com a promulgação, no ano de 2017, da Base Nacional Comum Curricular (BNCC) para a educação infantil e ensino fundamental. Este documento oficial se apresenta como sucessor aos PCN, cuja elaboração e promulgação foram acompanhadas pelos diversos canais midiáticos com manchetes como, por exemplo, "Base Curricular inclui temas como gênero e sexualidade em área de ensino religioso"4, "Governo Temer esvazia gênero na base curricular e mistura tema com religião"5, ou ainda "MEC retira termo 'orientação sexual' da versão final da Base Curricular"6.

Em face de tal cenário, cabe-nos indagar: Quais as concepções de diversidade sexual e de gênero são expressas pela BNCC? Quais possíveis silenciamentos sobre esta temática ecoam neste documento oficial? Quais subsídios a BNCC oferece aos docentes para o trabalho com estas temáticas no ambiente escolar? Quais as potencialidades e/ou deficiências deste documento no tratamento da sexualidade e do gênero? Destarte, a presente investigação objetivou verificar as possíveis concepções de diversidade sexual e de gênero presentes na BNCC (BRASIL, 2017), bem como analisar em que medida o documento oficial poderá subsidiar o trabalho docente no que se refere a atuações relativas à temática diversidade sexual e de gênero.

\section{Fundamentação teórica}

Embora a sexualidade permeie os muros escolares mediante as várias relações que se estabelecem entre os sujeitos que compõem a comunidade escolar, seu entrelaçamento com a educação ocorre, em nosso país, de modo sistematizado e enquanto política pública entre as décadas de 1920 e 1930. Nesse período, o Brasil combatia uma epidemia de sífilis e coube às instituições escolares, por meio da educação sexual, contribuir para o enfrentamento deste problema de saúde pública. As práticas educativas possuíam uma perspectiva médico-higienista sobre a sexualidade que, dentre outros aspectos, preconizava que a veiculação de informações sobre anatomia e fisiologia dos sistemas reprodutivos humanos contribuiria com mudanças na

\footnotetext{
${ }^{4}$ Disponível em: https://educacao.estadao.com.br

${ }^{5}$ Disponível em: https://www1.folha.uol.com.br

${ }^{6}$ Disponível em: http://agenciabrasil.ebc.com.br
} 
conduta sexual dos indivíduos (CASTRO; ABRAMOVAY; SILVA, 2004; ALTMANN, 2006, 2013; ABREU; SANTOS, 2015; LOURO, 2018).

Nas décadas subsequentes, sobretudo entre os anos de 1960 e 1980, observaram-se avanços e retrocessos na educação sexual promovida pelas escolas. Estes movimentos ocorreram dado, sobremaneira, ao contexto político-ditatorial vivenciado em nosso país, à (des)responsabilização familiar na promoção da educação sexual de crianças e adolescentes e às intervenções de grupos/setores religiosos e/ou conservadores da sociedade que apregoavam que a educação sexual não figurava dentre as funções sociais da escola (CASTRO; ABRAMOVAY; SILVA, 2004; ALTMANN, 2006; 2013; ABREU; SANTOS, 2015; LOURO, 2018).

Em decorrência desta dinâmica, o final da década de 1980 e início dos anos de 1990 foram marcados por experiências isoladas a partir de diretrizes educacionais de caráter difuso no que se refere à abordagem da sexualidade no ambiente escolar. Embora esparsas, tais experiências guardavam semelhanças, como, por exemplo, a abordagem de conteúdo como Infeções Sexualmente Transmissíveis (IST) e gravidez precoce por meio de perspectivas estritamente biológicas (e higienistas) (CASTRO; ABRAMOVAY; SILVA, 2004; ALTMANN, 2006; 2013; ABREU; SANTOS, 2015; LOURO, 2018).

A partir da segunda metade da década de 1990, as práticas educativas referentes à diversidade sexual e de gênero adquiriram nova tônica com a promulgação, no ano de 1996, dos Parâmetros Curriculares Nacionais (PCN), com ênfase no volume Tema Transversal Orientação Sexual. Resguardadas as discussões sobre o contexto neoliberal que permeou a promulgação dos PCN, diversos pesquisadores indicam que as pesquisas sobre este documento oficial compreendem um contínuo em que: um dos extremos indica de que os PCN representam uma possibilidade de repensar práticas educativas e formular políticas públicas sobre diversidade sexual e de gênero de modo a contemplar as múltiplas realidades que atravessam a escola; e em outro extremo, os PCN são compreendidos como um instrumento que se volta para o controle da saúde pública, dada a apresentação da temática sob vieses majoritariamente biológicos (CASTRO; ABRAMOVAY; SILVA, 2004; ALTMANN, 2006; 2013; ABREU; SANTOS, 2015).

Ao considerarmos as investigações que apontam para as potencialidades dos PCN no que tange à educação sexual, encontramos discursos que assinalam que este documento oficial legitima a abordagem da diversidade sexual e de gênero no ambiente escolar. Tal fato apresentase como uma inovação em termos de políticas públicas, oficializando a educação sexual como uma competência escolar e resguardando a atuação de docentes que desenvolvem atividades 
e/ou projetos que contemplam esta temática. Conjuntamente, a educação sexual é evidenciada como tema transversal, ou seja, como tema que atravessa todas as áreas do conhecimento e cuja abordagem deve ocorrer pelos professores dos diferentes componentes curriculares e em todos os níveis de ensino (LEÃO; RIBEIRO, 2012; VIANNA, 2012).

Todavia, tais inovações são problematizadas por Rocha (2011) e Fernandes (2016), que, dentre outros elementos, sinalizam que os PCN não possuem caráter obrigatório, configurandose como referencial curricular que poderá ou não ser seguido pelas instituições escolares. Por esta lógica, os PCN se caracterizam como documentos marginais, isto é, como documentos que poderão ecoar nas escolas de modo integral, parcial ou nulo. Os autores ressaltam ainda que o caráter transversal preconizado pelos PCN pode contribuir para a manutenção do trabalho da educação sexual no âmbito das disciplinas de Ciências (Ensino Fundamental) e Biologia (Ensino Médio), pois a transversalidade expressa pelo documento se apresenta de forma tênue, permitindo a docentes que atuam em áreas distintas das Ciências da Natureza alegarem que seus componentes curriculares não oportunizam a abordagem de assuntos relativos à diversidade sexual e de gênero.

Cabe ainda evidenciar que os PCN foram elaborados e promulgados em um contexto histórico e social no qual nosso país enfrentava uma epidemia de HIV/AIDS e era observado também um crescente índice de gravidez entre as adolescentes. Este cenário remete à compreensão da escola enquanto instituição social que promove e dissemina informações que levariam os sujeitos a práticas de sexo seguro, perspectiva similar àquela desenvolvida no momento em que o Brasil confrontava a epidemia de sífilis na década de 1920 (ABREU; SANTOS, 2015). Ainda por este ângulo, ao contrastarmos os blocos temáticos presentes nos PCN Tema Transversal Orientação Sexual (a saber, "Corpo e Matriz para a Sexualidade”, "Relações de Gênero" e "Prevenção às DST e Aids") com o contexto citado, verificamos forte ênfase no trinômio corpo-saúde-doença, remetendo-nos à perspectiva biológica e médica sobre a sexualidade (LEÃO; RIBEIRO, 2012; VIANNA, 2012).

No que concerne às questões de gênero, sua mobilização pelos PCN ocorre, na maioria das ocasiões, a partir de uma concepção biológica, ou seja, o conceito gênero é empregado como sinonímia do conceito sexo. Ao considerarmos tal sinonímia à luz das intenções que subjazem os PCN, constatamos que há pouquíssimos subsídios para que professores desenvolvam atividades e/ou projetos que levem crianças e adolescentes a pensarem questões 
de gênero enquanto constructos culturais e sociais passíveis de indagação e contestação (VIANNA; UNBEHAUM, 2004; ABREU; SANTOS, 2015; PALMA et al., 2015).

Considerando as problemáticas que emergem dos $\mathrm{PCN}$ no que se refere à diversidade sexual e de gênero, com ênfase em processos de silenciamento do conceito gênero, Palma et al. (2015, p. 737) afirmam que esta abordagem dos PCN

Pode ser entendida como uma estratégia de ação, que ao invés de provocar um enfrentamento que poderá ser coibido por setores conservadores da sociedade, apresenta uma proposta que tangencia a temática, ainda considerada polêmica, para que possa servir como um início de possibilidade de transformação social.

O entendimento expresso pelos autores leva-nos a crer que as problemáticas apontadas pela literatura resultam de "concessões" no campo da educação sexual que visariam futuros avanços quanto ao debate sobre diversidade sexual e de gênero no ambiente escolar. Esta interpretação, por sua vez, conduz-nos a hipóteses de futuros que variam entre profundos retrocessos ou avanços significativos na área, fato que deve figurar como um dos principais itens da agenda de pesquisas em sexualidade e educação, sobremaneira no que se refere à análise de documentos oficiais que incidem na elaboração de matrizes curriculares.

Essa justificativa torna-se proeminente quando consideramos os embates que surgiram ao longo da elaboração e da promulgação da BNCC. Sevilla e Seffner (2017) nos apontam que polêmicas e disputas, sobremaneira as erigidas por setores conservadores da sociedade, resultaram em um documento em que as ciências humanas são pouco valorizadas e questões relativas à diversidade sexual e de gênero foram escamoteadas. Segundo os autores:

Esses grupos articulam discursos conservadores de diversas ordens vinculados a questões morais e religiosas, defendem uma posição política em relação à função do Estado e da escola, restringindo estas instituições, defendendo liberdades individuais e os direitos e a liberdade da família em educar os seus filhos. Desta forma, acreditam que a escola não deve abordar temas como política, religião, gênero e sexualidade, que professores em sua maioria são "doutrinadores" e não são educadores, pois deveriam apenas se restringir a ensinar conteúdos técnicos. Tais concepções tomam os jovens como meras tábulas rasas, sem opinião e reflexão. Baseados nisso, defendem a proibição de professores e da escola de trabalhar estas temáticas, previstas nos parâmetros curriculares nacionais, que, como vimos, são caras não só aos movimentos sociais, como também aos próprios princípios democráticos, ferindo a autonomia pedagógica e atingindo a promoção da cidadania e a construção de uma escola plural, onde todos e todas devem ser respeitados, 
independentemente de sua origem, cor, etnia/raça, gênero, classe, identidade, orientação sexual, pertencimento religioso, etc. (p. 4-5).

Nesta perspectiva e considerando as afirmações de Palma et al. (2015), cabe-nos indagar: em que medida a BNCC se configura enquanto possibilidade de transformação social ao ponderarmos sobre a diversidade sexual e de gênero? $\mathrm{O}$ documento oficial expressa avanços, estagnações ou retrocessos sobre esta temática?

\section{Percurso metodológico}

Em concordância com o paradigma qualitativo que orientou este trabalho, adotamos enquanto procedimento metodológico a análise documental. Documentos, além de conterem informações relativas ao comportamento humano, voltam-se a objetivos específicos e constituem dispositivos comunicacionais impregnados pela realidade histórica e social de sua produção. Cabe também mencionar que documentos representam uma fonte natural e segura de dados que se mantêm ao longo do tempo e permitem sua consulta por diversos pesquisadores. Por este ângulo, dados oriundos de análises documentais possibilitam a identificação de problemáticas subjacentes que poderão ser exploradas em investigações posteriores com a complementação, ou não, de outros procedimentos metodológicos (FLICK, 2009).

Para a realização desta investigação, elegemos a BNCC (BRASIL, 2017) como documento passível de análise. Sua escolha justifica-se pelo fato deste documento oficial se configurar como a mais recente iniciativa do Ministério da Educação em regular o conjunto de aprendizagens, expressas em habilidades e competências, consideradas como necessários para a educação básica nacional no que tange à educação infantil e ao ensino fundamental. Além de sua atualidade, a BNCC se apresenta, de acordo com materiais disponíveis no endereço eletrônico: http://basenacionalcomum.mec.gov.br/, como documento oficial normativo, isto é, como documento que deverá ser seguido integralmente por todas as escolas da federação, opondo-se ao caráter orientador dos PCN.

Com vistas a compreender as concepções de sexualidade e gênero que pautam a BNCC e em que medida esse documento oficial subsidia a prática docente no que se refere a tal temática, pesquisamos no documento as seguintes palavras-chave: "diversidade sexual", "sexualidade", “direitos humanos", "preconceito”, "direitos sexuais", "direitos reprodutivos", "gênero", "orientação sexual”, "educação sexual”, “doenças sexualmente transmissíveis", “infecções sexualmente transmissíveis", "gravidez", “corpo biológico", “corpo humano", 
"reprodução", "saúde sexual", "saúde reprodutiva" e "prazer". Justificamos a escolha de tais palavras-chave uma vez que os termos empregados nos possibilitariam levantar informações mais amplas quanto à diversidade sexual e de gênero no documento analisando, de modo a abarcar aspetos biológicos, culturais, históricos, sociais, etc. Justificamos ainda a inclusão das expressões "gênero" e "orientação sexual", embora anunciada pela mídia sua retirada na ocasião da promulgação da BNCC, uma vez que consideramos necessária a caracterização amparada pela literatura pertinente de possíveis silenciamentos e tratamentos marginais desta temática.

Os dados levantados foram coligidos e analisados segundo a Análise Textual Discursiva (MORAES, 2003; MOARES; GALIAZZI, 2006), que corresponde a um processo de emersão de compreensões sobre o material em análise por meio de uma sequência recursiva, a saber: a unitarização (desconstrução textual do documento em análise), a categorização (estabelecimento de relações entre as unidades elaboradas à luz do referencial teórico adotado) e captação do novo emergente (compreensões desenvolvidas ao longo da teorização).

A Análise Textual Discursiva corresponde a um procedimento analítico não linear, configurando-se como ciclos de desestabilizações da ordem de materiais textuais. Por este ângulo, este procedimento analítico permite ao pesquisador elaborar nova ordem e nova compreensão a partir de elementos que se repetem e/ou se omitem nos materiais textuais. Destarte, a Análise Textual Discursiva compreende um processo analítico aberto, favorecedor do pensamento investigativo, visto que a realidade em estudo não se apresenta imediatamente passível de descrição e análise (MORAES, 2003; MOARES; GALIAZZI, 2006).

\section{Resultados e discussão}

Ao considerarmos a BNCC à luz do referencial teórico que orientou o presente estudo e dos pressupostos da Análise Textual Discursiva, três temáticas emergiram ao longo de nossa análise documental, a saber: sexualidade em sua dimensão biológica, silenciamento das questões de gênero e superficialidade no tratamento dos direitos humanos.

A primeira temática de análise, sexualidade em sua dimensão biológica, diz respeito às concepções de sexualidade expressas pela BNCC e aos subsídios que o referido documento oferece aos docentes. Tal temática se manifestou a partir da análise da mobilização das expressões "diversidade sexual", "sexualidade", "gênero", “orientação sexual”, "educação sexual", "doenças sexualmente transmissíveis", "infecções sexualmente transmissíveis", 
"gravidez”, “corpo biológico", “corpo humano”, "reprodução”, “saúde sexual”, "saúde reprodutiva" e "prazer" pelo documento analisado, assim como suas omissões no decorrer do texto oficial.

Ao considerarmos as alusões à temática sexualidade na BNCC, de maneira explícita e/ou implícita, verificamos que estas se concentram na seção destinada às Ciências da Natureza, especificamente ao componente curricular Ciências, e são ausentes nas demais áreas do conhecimento. Além de situar a sexualidade dentre as competências das Ciências da Natureza para o ensino fundamental, o documento oficial a associa a conceitos vinculados à saúde e à qualidade de vida, como podemos verificar no excerto abaixo.

\begin{abstract}
Nos anos finais, são abordados também temas relacionados à reprodução e à sexualidade humana, assuntos de grande interesse e relevância social nessa faixa etária, assim como são relevantes, também, o conhecimento das condições de saúde, saneamento básico, da qualidade do ar e das condições nutricionais da população brasileira.

Pretende-se que os estudantes, ao terminarem o Ensino Fundamental, estejam aptos a compreender a organização e o funcionamento de seu corpo, assim como interpretar as modificações físicas e emocionais que acompanham a adolescência e a reconhecer o impacto que elas podem ter na autoestima e na segurança do seu próprio corpo. É também fundamental que tenham condições de assumir o protagonismo na escolha de posicionamentos que representem autocuidado com seu corpo e respeito com o corpo do outro, na perspectiva do cuidado integral à saúde física, mental, sexual e reprodutiva. Além disso, os estudantes devem ser capazes de compreender o papel do Estado e das políticas públicas (campanhas de vacinação, programas de atendimento à saúde da família e da comunidade, investimento em pesquisa, campanhas de esclarecimento sobre doenças e vetores, entre outros) no desenvolvimento de condições propícias à saúde (BRASIL, 2017, p. 325).
\end{abstract}

Cabe salientar que, além desta delimitação curricular, a abordagem da sexualidade é restrita ao contexto do oitavo ano do Ensino Fundamental, figurando ao lado de conteúdos relativos a mecanismos reprodutivos, puberdade, gravidez e infecções sexualmente transmissíveis, como podemos verificar no Quadro 1:

Quadro 1 - Habilidades relativas ao ensino-aprendizagem de Ciências para o oitavo ano do Ensino Fundamental segundo Unidade Temática Vida e evolução

\begin{tabular}{|c|c|c|c|}
\hline $\begin{array}{c}\text { Unidade } \\
\text { Temática }\end{array}$ & $\begin{array}{c}\text { Objetos De } \\
\text { Conhecimento }\end{array}$ & \multicolumn{1}{|c|}{ Habilidades } \\
\hline $\begin{array}{c}\text { Vecanismos } \\
\text { reprodutivos } \\
\text { evolução }\end{array}$ & $\begin{array}{l}\text { (EF08CI07) Comparar diferentes processos reprodutivos } \\
\text { em plantas e animais em relação aos mecanismos } \\
\text { adaptativos e evolutivos. } \\
\text { (EF08CI08) Analisar explicar as transformações que } \\
\text { ocorrem na puberdade considerando a atuação dos } \\
\text { hormônios sexuais e do sistema nervoso. }\end{array}$ \\
\hline
\end{tabular}




\begin{tabular}{|l|l|}
\hline & (EF08CI09) Comparar o modo de ação e a eficácia dos \\
& diversos métodos contraceptivos e justificar a necessidade \\
de compartilhar a responsabilidade na escolha e na \\
utilização do método mais adequado à prevenção da \\
gravidez precoce e indesejada e de Doenças Sexualmente \\
Transmissíveis (DST). \\
(EF08CI10) Identificar os principais sintomas, modos de \\
transmissão e tratamento de algumas DST (com ênfase na \\
AIDS), e discutir estratégias e métodos de prevenção. \\
(EF08CI11) Selecionar argumentos que evidenciem as \\
múltiplas dimensões da sexualidade humana (biológica, \\
sociocultural, afetiva e ética).
\end{tabular}

Fonte: Brasil (2017, p. 346-347)

Face ao exposto, a sexualidade é apresentada pela BNCC somente em sua dimensão biológica, na qual são salientados conteúdos vinculados à anatomia e à fisiologia da reprodução humana. Cabe sublinhar que ao apresentar o corpo biológico ao lado de conteúdos referentes às IST, denominadas no documento oficial ainda pela nomenclatura DST (Doenças Sexualmente Transmissíveis) ${ }^{7}$, o trabalho com tal temática em sala de aula poderá reforçar o trinômio corpo-saúde-doença que, dentre outros aspectos, traz em si pressupostos médicohigienistas. Por este ângulo, a sexualidade adquire conotações de controle de condutas sexuais com vistas a minimizar problemas de saúde pública, sejam aqueles vinculados ao contágio e transmissão de IST, sejam aqueles referentes aos índices de gravidez na adolescência. Destarte, observamos que a BNCC se reveste das mesmas problemáticas que Leão e Ribeiro (2012), Vianna (2012) e Abreu e Santos (2015) indicaram nos PCN, fato que nos leva a crer que discussões acerca da educação sexual não apresentaram avanços ao longo das duas décadas que separam ambos os documentos oficiais da educação básica.

Cabe ainda ressaltar que a décima primeira habilidade preconizada para o oitavo ano do ensino fundamental no contexto da disciplina de Ciências, a saber, "Selecionar argumentos que evidenciem as múltiplas dimensões da sexualidade humana (biológica, sociocultural, afetiva e ética)" (BRASIL, 2017, p. 346-347), apresenta fragilidades que poderão levar ao seu não desenvolvimento ou desenvolvimento falho pelos estudantes. Ao considerarmos o contexto de habilidades que a antecede, verificamos que o documento oficial não subsidia o professor a planejar sua atuação de modo a contemplar as múltiplas dimensões da sexualidade, dado que a

\footnotetext{
${ }^{7}$ Segundo o endereço eletrônico do Departamento de Vigilância, Controle e Prevenção das IST, do HIV/Aids e das Hepatites Virais vinculado ao Ministério da Saúde, http://www.aids.gov.br, "A terminologia Infecções Sexualmente Transmissíveis (IST) passa a ser adotada em substituição à expressão Doenças Sexualmente Transmissíveis (DST), porque destaca a possibilidade de uma pessoa ter e transmitir uma infecção, mesmo sem sinais e sintomas".
} 
BNCC enfatiza apenas aspectos biológicos em detrimento de outras dimensões que atravessam a sexualidade humana. No que concerne à prática docente, Castro, Abramovay e Silva (2004), Vieira e Matsukura (2017), Furlanetto e colaboradores (2018) e Riza, Ribeiro e Mota (2018) nos indicam que, além de deficiências formativas, os professores enfrentam dificuldades com trabalhos que envolvam a sexualidade devido a crenças e valores que possuem, fato que nos aponta que as dimensões sociocultural, afetiva e ética da sexualidade prescritas pela BNCC poderão ser escamoteadas ao longo dos processos de ensino-aprendizagem.

Quanto à segunda temática de análise, silenciamento das questões de gênero, sua manifestação ocorreu devido a não menção, explícita e/ou implícita, do termo gênero ao longo da BNCC, fato já aludido pela mídia na ocasião da promulgação do documento. Vianna e Unbehaum (2004), Abreu e Santos (2015) e Palma e colaboradores (2015) problematizaram a abordagem das questões de gênero tão somente pelo viés biológico pelos PNC, apontando o modo como o documento oficial tomava gênero e sexo como sinônimos e suas implicações para a atuação docente, o que implica na ratificação e naturalização do binarismo de gênero e da heteronormatividade. Por este ângulo, ao constatar que a BNCC silencia quaisquer discussões sobre gênero, verificamos que o documento oficial vai de encontro às argumentações tecidas pela literatura pertinente, situação que, em última instância, poderá colaborar para a manutenção de misoginia, homofobia, lesbofobia, transfobia, etc., no ambiente escolar.

Este fato se torna problemático ao considerarmos que a BNCC orientará a elaboração de matrizes curriculares da educação básica em todo o território nacional, pois a não abordagem do gênero no corpo do documento abrirá precedentes para que esta temática não seja incluída nos processos educativos. Vianna e Unbehaum (2004) salientam que é desejável e necessária a menção do conceito gênero em documentos oficiais voltados à educação e que sua omissão oculta desigualdades sob a égide de modelos linguísticos. Fernandes (2016), por sua vez, advoga que silenciamentos como o descrito em políticas públicas educacionais inviabilizam o questionamento, no ambiente escolar, de dimensões micro e macrossociais imanentes à diversidade sexual e de gênero, reiterando práticas discriminatórias que, dentre outros aspectos, levam à manutenção de desigualdades.

Finalmente, a terceira temática de análise, superficialidade no tratamento dos direitos humanos, refere-se às concepções de diversidade mobilizadas pela BNCC, com ênfase na diversidade sexual e de gênero, e aos subsídios que o referido documento oferece aos docentes. Esta categoria emergiu a partir do emprego e/ou omissão dos termos "diversidade sexual", 
"direitos humanos", "preconceito", "direitos sexuais", "direitos reprodutivos", "gênero" e “orientação sexual” pelo documento analisado.

O conceito de direitos humanos é mobilizado ao longo de todas as áreas do conhecimento, sendo sua promoção apresentada enquanto competência geral de cada área do saber e de cada componente curricular. Embora exaustivamente empregado pela BNCC, o conceito de direitos humanos carece de conceituação, de maneira que sua utilização genérica poderá resultar em compreensões simplistas sobre o respeito à diversidade. Por este ângulo, a diversidade digna de respeito guardará equivalências com a leitura de mundo que o docente possui e, sendo assim, cabe-nos indagar: qual diversidade deverá ser respeitada e em quais contextos sociais?

Esta abordagem genérica também é utilizada pela BNCC ao mobilizar o conceito preconceito ao longo das competências específicas das áreas do conhecimento, sendo comumente empregada a expressão "sem preconceitos de qualquer natureza". Esta configuração se apresenta de modo diferenciado quando consideramos as competências gerais para o componente curricular Educação Física para o ensino fundamental, sobremaneira as competências 4 e 5 , que preconizam:

4. Identificar a multiplicidade de padrões de desempenho, saúde, beleza e estética corporal, analisando, criticamente, os modelos disseminados na mídia e discutir posturas consumistas e preconceituosas.

5. Identificar as formas de produção de preconceitos, compreender seus efeitos e combater posicionamentos discriminatórios em relação às práticas corporais e aos seus participantes (BRASIL, 2017, p. 221).

Em um primeiro momento, tais competências nos levam a ponderar sobre possibilidades de os educadores físicos trabalharem com o conceito diversidade, com ênfase em diversidade de gênero. Nesta perspectiva, os docentes poderiam oportunizar situações para (des)construções acerca dos corpos feminino e masculino, bem como suas possibilidades e potencialidades de expressão. Todavia, além de esbarramos em problemáticas imanentes às deficiências formativas de professores no que concerne à diversidade sexual e de gênero (CASTRO; ABRAMOVAY; SILVA, 2004; SEFFNER; PICCHETTI, 2014; VIEIRA; MATSUKURA, 2017; FURLANETTO et al., 2018; RIZA; RIBEIRO; MOTA, 2018), a BNCC mobiliza o conceito preconceito em três habilidades específicas para o componente curricular Educação Física, circunscrevendo-o em contextos étnico-culturais $\left(3^{\circ}\right.$ ao $5^{\circ}$ ano e $6^{\circ}$ ao $7^{\circ}$ ano) e geracionais ( $8^{\circ}$ ao $9^{\circ}$ ano), como podemos observar no Quadro 2. 
Quadro 2 - Habilidades relativas ao ensino-aprendizagem de Educação Física para o Ensino Fundamental segundo Unidades Temáticas em que há a mobilização do conceito preconceito

\section{$3^{\circ}$ ao $5^{\circ}$ ano - Unidade Temática: Danças}

(EF35EF09) Experimentar, recriar e fruir danças populares do Brasil e do mundo e danças de matriz indígena e africana, valorizando e respeitando os diferentes sentidos e significados dessas danças em suas culturas de origem.

(EF35EF10) Comparar e identificar os elementos constitutivos comuns e diferentes (ritmo, espaço, gestos) em danças populares do Brasil e do mundo e danças de matriz indígena e africana.

(EF35EF11) Formular e utilizar estratégias para a execução de elementos constitutivos das danças populares do Brasil e do mundo, e das danças de matriz indígena e africana. (EF35EF12) Identificar situações de injustiça e preconceito geradas e/ou presentes no contexto das danças e demais práticas corporais e discutir alternativas para superá-las.

\section{$6^{\circ}$ ao $7^{\circ}$ ano - Unidade Temática: Lutas}

(EF67EF14) Experimentar, fruir e recriar diferentes lutas do Brasil, valorizando a própria segurança e integridade física, bem como as dos demais.

(EF67EF15) Planejar e utilizar estratégias básicas das lutas do Brasil, respeitando o colega como oponente.

(EF67EF16) Identificar as características (códigos, rituais, elementos técnico-táticos, indumentária, materiais, instalações, instituições) das lutas do Brasil.

(EF67EF17) Problematizar preconceitos e estereótipos relacionados ao universo das lutas e demais práticas corporais, propondo alternativas para superá-los, com base na solidariedade, na justiça, na equidade e no respeito.

\section{$8^{\circ}$ ao $9^{\circ}$ ano - Unidade Temática: Danças}

(EF89EF12) Experimentar, fruir e recriar danças de salão, valorizando a diversidade cultural e respeitando a tradição dessas culturas.

(EF89EF13) Planejar e utilizar estratégias para se apropriar dos elementos constitutivos (ritmo, espaço, gestos) das danças de salão.

(EF89EF14) Discutir estereótipos e preconceitos relativos às danças de salão e demais práticas corporais e propor alternativas para sua superação.

(EF89EF15) Analisar as características (ritmos, gestos, coreografias e músicas) das danças de salão, bem como suas transformações históricas e os grupos de origem.

Fonte: Brasil, 2017 (Grifos nossos)

Sendo assim, observamos direcionamentos para o tratamento do preconceito que, aliados à leitura de mundo que o educador físico possui e as deficiências formativas apontadas pela literatura, redundarão em práticas que desconsiderarão questões vinculadas à diversidade de gênero. Cabe finalmente destacar que, ao discorrer sobre o compromisso com a educação integral em sua introdução, a BNCC emprega o conceito preconceito, afirmando que seu ensino-aprendizagem deve se fortalecer por meio de práticas coercitivas:

Nesse contexto, a BNCC afirma, de maneira explícita, o seu compromisso com a educação integral. Reconhece, assim, que a Educação Básica deve visar à formação e ao desenvolvimento humano global, o que implica compreender a complexidade e a não linearidade desse desenvolvimento, rompendo com visões reducionistas que privilegiam ou a dimensão intelectual (cognitiva) ou 
a dimensão afetiva. Significa, ainda, assumir uma visão plural, singular e integral da criança, do adolescente, do jovem e do adulto - considerando-os como sujeitos de aprendizagem - e promover uma educação voltada ao seu acolhimento, reconhecimento e desenvolvimento pleno, nas suas singularidades e diversidades. Além disso, a escola, como espaço de aprendizagem e de democracia inclusiva, deve se fortalecer na prática coercitiva de não discriminação, não preconceito e respeito às diferenças e diversidades (BRASIL, 2017, p. 14) (Grifos nossos).

Destarte, o documento oficial levanta um paradoxo ao articular preconceito e práticas repressivas e/ou punitivas para o seu ensino-aprendizagem. Ao ponderar sobre tal afirmação à luz dos apontamentos realizados pela literatura em diversidade sexual e de gênero no ambiente escolar, somos levados a indagar: quem serão os sujeitos-alvo de repressões e punições em situações em que o diverso se encontra na escola? Neste cenário, advogamos que tal construção argumentativa se mostra tão ou mais temerária quanto o silenciamento apontado para as questões de gênero.

Fundamentada em meio à heteronormatividade, a escola se torna terreno fértil à disseminação e reprodução de padrões heteronormativos e, consequentemente, converte-se em espaço violento à diversidade sexual e de gênero (POCAHY; DORNELLES, 2010; BENTO, 2011). Nesta perspectiva, a sexualidade de crianças e adolescentes é percebida e trabalhada de modo a enfatizar o corpo biológico em detrimento de outros elementos constituintes da sexualidade e a ratificar e reiterar a naturalização do binarismo de gênero e da heteronormatividade (CASTRO; ABRAMOVAY; SILVA, 2004; SEFFNER; PICCHETTI, 2014; LOURO, 2018). Destarte, a busca pelo respeito à diferença expressa pelo documento oficial poderá se transfigurar em seu silenciamento e ocultamento, em que crianças e adolescentes que fujam aos pressupostos heteronormativos poderão ser coagidos, por meio de mecanismos normatizadores, a seguir padrões impostos sob a égide do impedimento, da discriminação, do preconceito e quaisquer outras violências.

Em suma, verificamos que a BNCC se apresenta refratária à diversidade sexual e de gênero na escola, de modo que suas preconizações exibem retrocessos na discussão de tal temática quando comparadas àquelas presentes nos PCN. Sendo assim, os apontamentos de Palma et al. (2015) no que concerne às concessões realizadas pelos PCN para a temática não representaram em si estratégias de enfrentamentos e questionamentos, mas se configuraram em silenciamentos da diversidade sexual e de gênero que germinavam naquele período. 


\section{Conclusões}

Ao voltarmos o olhar para nossos objetivos, constatamos que a BNCC limita a sexualidade unicamente em sua dimensão biológica, associando-a à prevenção de IST e gravidez na adolescência, aproximando-se, assim, de concepções médico-higienistas sobre a temática. Por esta lógica, a BNCC apresenta retrocessos quando comparada aos PCN, sobremaneira o documento Tema Transversal Orientação Sexual, visto que o documento do final da década de 1990 apregoava que questões referentes à sexualidade deveriam ser trabalhadas pelos docentes das diferentes áreas do conhecimento. No que concerne à diversidade de gênero, embora a literatura aponte para problemáticas na sua abordagem pelos PCN, observamos a ocorrência de silenciamentos mais profundos desta temática na BNCC. Juntamente a tal ausência, verificamos ainda que o documento oficial analisado trata os conceitos direitos humanos e preconceito de maneira genérica, fato que poderá intensificar os silenciamentos destacados.

Destarte, as constatações realizadas por este estudo trazem à tona obstáculos para a elaboração de atividades, discussões e/ou projetos sobre diversidade sexual e de gênero no ambiente escolar, visto que seu tratamento pela BNCC e a ausência de subsídios aos docentes poderão redundar na marginalização da sexualidade e do gênero na escola. Por este ângulo, e considerando as deficiências formativas da docência apontadas pela literatura, somos levados a crer que os tênues avanços possibilitados pelos PCN poderão ruir diante da implantação da BNCC na educação básica, representada pela educação infantil e ensino fundamental.

Diante deste cenário que se levanta, faz-se necessário que as pesquisas em diversidade sexual e de gênero no ambiente escolar voltem seus esforços para traçar panoramas sobre as repercussões da BNCC nas escolas de nosso país. Nesta perspectiva, será preciso que a universidade, em parceria com a educação básica, trace uma agenda de pesquisa na área com o intuito de levantar possíveis compreensões da comunidade escolar sobre a BNCC e suas diretrizes, verificar a permeabilidade da BNCC na elaboração de grades curriculares e materiais didáticos, caracterizar ofertas de processos formativos à docência, compreender o planejamento e a condução de atividades de ensino-aprendizagem que contemplem questões relativas à diversidade sexual e de gênero, etc. Por esta lógica, os achados de pesquisas futuras contribuiriam com possíveis indicações que auxiliariam docentes a transporem os retrocessos que o documento oficial apresenta. 
AGRADECIMENTOS: Programa de Educação em Direitos Humanos \& Diversidades executado pela Capes em parceria com a Secretaria de Educação Continuada, Alfabetização, Diversidade e Inclusão - SECADI, do Ministério da Educação - MEC.

\section{REFERÊNCIAS}

ABREU, R. L. P.; SANTOS, R. A. P. Gênero e sexualidade nos PCNs: uma análise dos objetivos gerais. Caderno Espaço Feminino, Uberlândia, v. 28, n. 1, p. 24-35, 2015.

ALTMANN, H. Sobre a educação sexual como um problema escolar. Revista Linhas, Florianópolis, v. 7, n. 1, p. 1-12, 2006.

ALTMANN, H. Diversidade sexual e educação: desafios para a formação docente. Sexualidad, Salud y Sociedad - Revista Latinoamericana, Rio de Janeiro, n. 13, p. 69-82, 2013.

BENTO, B. Na escola se aprende que a diferença faz a diferença. Estudos feministas, Florianópolis, v. 19, n. 2, p. 548-559, 2011.

BRASIL. Base Nacional Comum Curricular. Brasília: MEC, 2017. Disponível em: http://basenacionalcomum.mec.gov.br/a-base. Acesso em: 01 mar. 2018.

CASTRO, M. G.; ABRAMOVAY, M.; SILVA, L. B. Juventudes e Sexualidades. Brasília: UNESCO Brasil, p. 29-47, 2004.

FERNANDES, C. Diversidade sexual e políticas educacionais: possíveis aproximações. In: FREITAS, L. G.; BRZEZINSKI, I. Políticas educacionais: neoliberalismo, formação de professores, tecnologia, diversidade e inclusão. Anápolis: Editora UEG, p. 377-395, 2016.

FLICK, U. Introdução à pesquisa qualitativa. 3. ed. Trad.: Joice Elias Costa. Porto Alegre: ArtMed, p. 230-237, 2009.

FURLANETTO, M. F. et al. Educação sexual em escolas brasileiras: revisão sistemática de literatura. Cadernos de Pesquisa, São Paulo, v. 48, n. 168, p. 550-571, 2018.

LEÃO, A. M. C.; RIBEIRO, P. N. M. As políticas educacionais do Brasil: a (in)visibilidade da sexualidade e das relações de gênero. Revista Ibero-Americana de Estudos em Educação, Araraquara, v. 7, n. 2, p. 28-37, 2012.

LOURO, G. L. Um corpo estranho: ensaios sobre a sexualidade e teoria queer. 3. ed. rev. amp. Belo Horizonte: Autêntica Editora, 2018.

MORAES, R. Uma tempestade de luz: a compreensão possibilitada pela análise textual discursiva. Ciência \& Educação, Bauru, v. 9, n. 2, p. 191-211, 2003.

MORAES, R.; GALIAZZI, M. C. Análise textual discursiva: processo reconstrutivo de múltiplas faces. Ciência \& Educação, Bauru, v. 12, n. 1, p. 117-128, 2006. 
PALMA, Y. A. et al. Parâmetros Curriculares Nacionais: um estudo sobre orientação sexual, gênero e escola no Brasil. Trends in Psychology/Temas em Psicologia, Ribeirão Preto, v. 23, n. 3, p. 727-738, 2015.

POCAHY, F.; DORNELLES, P. G. Um corpo entre o gênero e a sexualidade: notas sobre educação e abjeção. Instrumento, Juiz de Fora, v. 1, n. 1, p. 125-135, 2010.

RIZZA, J. L.; RIBEIRO, P. R. C.; MOTA, M. R. A. A sexualidade nos cursos de licenciatura e a interface com políticas de formação de professores/as. Educação e Pesquisa, São Paulo, v. 44, p. 1-18, 2018.

ROCHA, K. A. Diversidade sexual e combate à homofobia no cenário das políticas públicas para a educação. In: Congresso Nacional de Educação, I Seminário Internacional de Representações Sociais, Subjetividade e Educação, 10, 2011, Curitiba. Anais [...] Curitiba: PUC - PR, 2011. Disponível em: http://educere.bruc.com.br/CD2011/pdf/5958_2939.pdf. Acesso em: 25 maio 2018.

SEFFNER, F.; PICCHETTI, Y. P. A escola pública brasileira e seu compromisso com a diversidade de gênero e sexualidade. In: MAGALHÃES, J. C.; RIBEIRO, P. R. C. (Org.) Educação para a sexualidade. Rio Grande: Ed. da Furg (Coleção Cadernos Pedagógicos da EaD), p. 67-82, 2014.

SEVILLA, G.; SEFFNER, F. A guinada conservadora na educação: reflexões sobre o novo contexto político e suas reverberações para a abordagem de gênero e sexualidade na escola. In: SEMINÁRIO INTERNACIONAL FAZENDO GÊNERO, 11 \& WOMEN'S WORLDS CONGRESS, 13, 2017, Florianópolis. Anais [...] Florianópolis: UFSC, 2017. Disponível em: http://www.en.wwc2017.eventos.dype.com.br/resources/anais/1499465018_ARQUIVO_texto completofazendogeneroversaofinalgabrielasevillaefernandoseffner.pdf. Acesso em 03 jan. 2019.

VIANNA, C. Gênero, sexualidade e políticas públicas de educação: um diálogo com a produção acadêmica. Pro-Posições, Campinas, v. 68, n, 2, p. 127-143, 2012.

VIANNA, C.; UNBEHAUM, S. O gênero nas políticas públicas de educação no Brasil: 19882002. Cadernos de Pesquisa, São Paulo, v. 34, n. 121, p. 77-104, 2004.

VIEIRA, P. M.; MATSUKURA, T. S. Modelos de educação sexual na escola: concepções e práticas de professores do ensino fundamental da rede pública. Revista Brasileira de Educação, Rio de Janeiro, v. 22, n. 69, 2017. 


\section{Como citar este artigo}

SILVA, Caio Samuel Franciscati; BRANCALEONI, Ana Paula Leivar; OLIVEIRA, Rosemary Rodrigues. Base Nacional Comum Curricular e diversidade sexual e de gênero: (des)caracterizações. Revista Ibero-Americana de Estudos em Educação, Araraquara, v. 14, n. esp. 2, p. 1538-1555, jul. 2019. E-ISSN: 1982-5587. DOI: 10.21723/riaee.v14iesp.2.12051

Submetido em: 30/09/2018

Revisões requeridas: 20/02/2019

Aprovado em: 30/04/2019

Publicado em: 26/06/2019 